\title{
Market Channel Procurement Strategy and School Meal Costs in Farm-to-School Programs
}

\author{
Jill Fitzsimmons $\odot$, and Jeffrey K. O’Hara $\odot$
}

\begin{abstract}
Farm-to-school (F2S) local food procurement must be cost-effective to be financially sustainable without policy support. We test, among schools participating in F2S programs, whether market channel procurement strategies for local foods affect schools' perceptions of whether meal costs decline as a result of F2S participation. Schools that buy local foods exclusively from intermediaries are 7 percentage points less likely to report lower costs from undertaking F2S initiatives. We further demonstrate that the probability that schools source local foods exclusively from intermediaries is influenced by the number of direct marketing farmers in their county.
\end{abstract}

Key Words: farm to school, food distribution, local food, school food

JEL Classifications: I28, Q13, Q18

\section{Introduction}

Schools participate in farm-to-school (F2S) programs to promote the well-being of students through agricultural and nutrition-related activities, such as serving local foods (Slusser et al. 2007; Joshi, Azuma, and Feenstra 2008; Benson 2014; Jones et al. 2015; National Farm to School Network [NFSN] 2016). F2S programming increased dramatically in the last two decades in the United States. In 1997, just six schools reported having an F2S program, but by 2014, 5,254 school districts reported having one (NFSN 2016; U.S. Department of Agriculture, Food and Nutrition Service [USDA-FNS] 2017). Local food procurement may add costs to school food programs, however, which could jeopardize the long-term sustainability of F2S programming. Additional costs to implement local sourcing result from staff effort required to procure and prepare local foods, equipment needs, or price premiums that local foods may command (Vo and Holcomb 2011; Boys and Fraser 2019). Public and private sector funding, like the U.S. Department of Agriculture's (USDA) Farm to School Grant Program, have been developed to alleviate F2S program implementation costs.

Jill Fitzsimmons, Department of Resource Economics, University of Massachusetts-Amherst, Amherst, MA, USA. Jeffrey K. O'Hara, U.S. Department of Agriculture, Agricultural Marketing Service, Washington, DC, USA. Correspondence: Jill Fitzsimmons, Department of Resource Economics, University of Massachusetts-Amherst, Amherst, MA, USA, Email: jfitzsim@resecon. umass.edu

Agricultural and Resource Economics Review 48/3 (December 2019) 388-413

(C) The Author(s) 2019. This is an Open Access article, distributed under the terms of the Creative

Commons Attribution licence (http://creativecommons.org/licenses/by/4.0/), which permits unrestricted re-use, distribution, and reproduction in any medium, provided the original work is 
One proposal to mitigate F2S costs is for "school food authorities" (SFAs) (schools or school districts that purchase foods for school meal programs) to procure local foods through market intermediaries like broadline distributors (Vogt and Kaiser 2008; Ralston et al. 2017). F2S procurement through intermediated market channels, instead of directly from farmers, might allow schools to leverage efficiencies of scale present in traditional supply chains for more cost-effective purchases. Our study provides perhaps the first national-level evidence that market channel procurement strategies for local sourcing influence whether meal costs decline from F2S programming.

We use F2S Census data to estimate, among schools with F2S programs, whether the market channels SFAs use to procure local foods influenced whether SFAs reported that school meal costs declined from F2S programming. We investigate three local food procurement strategies: purchasing directly from farmers exclusively, purchasing from intermediaries exclusively, and purchasing from both farmers and intermediaries. We construct "problem" variables to control for implementation barriers that the F2S literature suggests increase costs. Problem variables include the full range of costs that are associated with ongoing F2S procurement, including both increases in food prices and additional implementation costs. Additional implementation costs may arise from time-consuming relationships with farmers, liability and insurance costs, lack of information, incompatible payment arrangements, extra staff needs, delivery challenges, lack of processed products, constraints on seasonal availability and product shelflife, and lack of local supply/farmers (Vogt and Kaiser 2008; Dimitri, Hanson, and Oberholtzer 2012). We create five categories of implementation costs: transaction (Hobbs 1997; Gregoire, Arendt, and Strohbehn 2005; Conner et al. 2014; Fitzsimmons and Lass 2015; Motta and Sharma 2016), price (Vo and Holcomb 2011), on-site preparation (Vogt and Kaiser 2008; Colasanti, Matts, and Hamm 2012), distribution (Gregoire, Arendt, and Strohbehn 2005; Oberholtzer, Dimitri, and Jaenicke 2014), and product availability (Vogt and Kaiser 2008; Oberholtzer, Dimitri, and Jaenicke 2014). At the school level, we further control for F2S program activities and the type of products purchased. Following Ralston et al. (2017) and Botkins and Roe (2018), we control for the demographic attributes, state, and proximate food environment of the SFAs.

Forty-three percent of SFAs source local foods from intermediaries exclusively, while $47 \%$ do so from both farmers and intermediaries. We find that SFAs that buy local foods exclusively from intermediaries (relative to SFAs that procure at least some local foods directly from farmers) are 7 percentage points less likely to report lower school meal costs from F2S programming. Similarly, SFAs that procure local foods from both farmers and intermediaries are 6 percentage points more likely to report lower school meal costs. We do not find a relationship between SFAs that procure local foods exclusively from farmers and school meal costs, likely because only $10 \%$ of SFAs source local foods this way. 
The 2013 and 2015 USDA-FNS F2S Censuses have enabled national-level studies of F2S programs. Several studies use F2S Census data to examine the determinants of F2S adoption (Lyson 2016; McCarthy, Steiner, and Houser 2017; Ralston et al. 2017; Botkins and Roe 2018; O'Hara and Benson 2019) but do not investigate the market channels that SFAs use. One exception is Christensen, Jablonski, and O'Hara (2019), who find a negative correlation between the local food expenditures of SFAs and whether they made local purchases directly from farmers and other nontraditional suppliers. While Christensen, Jablonski, and O'Hara (2019) focus on food expenditures, we model aggregate school meal costs. This latter variable encompasses expenditures for food, as well as nonfood transaction and implementation costs. These aggregate costs are the measure that is relevant for F2S policy. This is because F2S grant assistance programs are designed to alleviate the nonfood implementation costs incurred from sourcing locally, not for subsidizing food purchases.

Our results contradict the hypothesis that intermediated F2S market channels, relative to direct market channels, are more likely to support the long-term viability of F2S procurement from efficiencies and economies of scale. Our research does not reveal the specific mechanism(s) by which SFAs experience reduced costs because of local purchases from farmers. Possible explanations include the following: farmers may supply foods to fulfill social goals, whereas intermediaries may supply foods to maximize profits (Fitzsimmons and Lass 2015; Lehnerd et al. 2018); intermediaries may not efficiently source local foods; and intermediaries may cost-effectively source local foods but do not pass savings from these efficiencies along to SFAs.

\section{Background Research and Literature}

\section{F2S and School Meal Costs}

Schools are a strategic venue to promote healthier food consumption (Centers for Disease Control and Prevention 2018). SFAs attempt to keep meal costs low without compromising participation rates among students or the nutritional content of the food. Although SFAs that provide government-funded school meals are intended to operate on a cost-recovery basis to maintain a balanced budget, some programs operate at a loss in practice (Ralston and Newman 2015).

Standard school-food implementation costs include costs of food purchasing, preparation, and program management. School food expenditures, or food purchasing costs, account for $46 \%$ of reported meal costs, while labor for food preparation and the food service portion of management comprise $45 \%$ of reported costs (Bartlett, Glantz, and Logan 2008). Food service operations are self-operated or contracted out to a food service management company but, regardless, are nested within an SFA's administrative management 
structure. Bartlett, Glantz, and Logan (2008) estimate that, on average, unreported costs account for $19 \%$ of total costs, about $61 \%$ of which is labor. School per meal costs vary depending on region; whether the school is in an urban, suburban, or rural area; and school size (Ollinger, Ralston, and Guthrie 2011; Ollinger and Guthrie 2015).

Local food procurement may increase the standard costs of school food programs because of the additional effort needed to gather information, negotiate, and monitor procurement (Motta and Sharma 2016). The effort required to deal with F2S-specific implementation costs generally appears as labor costs and manifests as additional staff hours dedicated to F2S procurement (Fitzsimmons and Lass 2015). On-site food preparation challenges raise costs. These costs arise from training food service staff how to cook with local foods (labor costs) or purchasing new kitchen equipment to more effectively cook local foods (capital expenses) (Colasanti, Matts, and Hamm 2012). Distribution challenges and poor product availability can also increase costs (Gregoire, Arendt, and Strohbehn 2005; Vogt and Kaiser 2008; Oberholtzer, Dimitri, and Jaenicke 2014). Finally, there may be a price premium associated with purchasing a local product.

The 2013-2014 F2S Census asked SFAs the kinds of problems they experienced when they procured local foods (Table 1). Product availability was the most widely reported problem (57\%). High prices were a problem for $38 \%$ of respondents, and procurement coordination was problematic for $26 \%$ of respondents. Overall, $75 \%$ of SFAs reported at least one procurement problem.

\section{Market Channel Structure and Costs}

Researchers have investigated the impact of increasing market consolidation in the food distribution system on food prices (Fitzsimmons, Lavoie, and Lass 2018; Sexton and Xia 2018; Brown and Tousey 2019). Research within the context of local food procurement suggests that market power in intermediated local food supply chains has an ambiguous impact on equilibrium prices and quantities, depending on the extent of market power and supply chain efficiencies (Fitzsimmons, Lavoie, and Lass 2018). Intermediaries may reduce supply costs for local food products relative to farmers by eliminating redundancies and accessing efficiencies of scale (Hortascu and Syverson 2007; Ashenfelter, Hosken, and Weinberg 2015). For example, intermediaries may reduce F2S-specific transaction costs associated with gathering information, negotiating terms, and enforcing terms (Hobbs 1997), as well as marketing costs like packaging and distribution. If intermediaries reduce these costs and pass the cost savings on to SFAs, school meal costs for local foods should be lower when procured through intermediaries rather than when procured directly from farmers.

On the other hand, procurement through intermediaries might increase costs to SFAs. Costs might increase if there are dis-economies of scale, if there are fixed adjustment costs that confront intermediaries in procuring local 
Table 1. Farm to School Implementation Procurement Problems (2013-2014)

\begin{tabular}{|c|c|c|}
\hline Type of Procurement Problem & $\begin{array}{l}\text { No. of Schools } \\
\text { Reporting } \\
\text { the Problem }\end{array}$ & $\begin{array}{l}\text { \% of Schools } \\
\text { Reporting } \\
\text { the Problem }\end{array}$ \\
\hline \multicolumn{3}{|l|}{ On-site } \\
\hline $\begin{array}{l}\text { Lack of kitchen equipment to process/prepare local } \\
\text { foods }\end{array}$ & 553 & $12 \%$ \\
\hline $\begin{array}{l}\text { Good Agricultural Practices (GAP) or other food safety } \\
\text { requirements }\end{array}$ & 552 & $12 \%$ \\
\hline $\begin{array}{l}\text { Lack of compliance with your institution's purchasing } \\
\text { regulations and policies }\end{array}$ & 275 & $6 \%$ \\
\hline \multicolumn{3}{|l|}{ Delivery } \\
\hline Lack of reliability in delivering ordered items & 874 & $19 \%$ \\
\hline Getting on-time deliveries & 393 & $8 \%$ \\
\hline Having quantity delivered equal to quantity ordered & 381 & $8 \%$ \\
\hline \multicolumn{3}{|l|}{ Price } \\
\hline Higher prices & 1,810 & $38 \%$ \\
\hline Unstable product prices & 729 & $15 \%$ \\
\hline \multicolumn{3}{|l|}{ Product } \\
\hline Hard to find year-round availability of key items & 2,674 & $57 \%$ \\
\hline Local items not available from primary vendors & 1,268 & $27 \%$ \\
\hline $\begin{array}{l}\text { Vendors for local items do not offer a broad range of } \\
\text { products }\end{array}$ & 1,033 & $22 \%$ \\
\hline Lack of availability of processed/precut products & 709 & $15 \%$ \\
\hline $\begin{array}{l}\text { Getting product delivered that meets your quality } \\
\text { requirements and other specifications (i.e., size) }\end{array}$ & 718 & $15 \%$ \\
\hline \multicolumn{3}{|l|}{ Transaction } \\
\hline Local producers are not bidding & 774 & $16 \%$ \\
\hline $\begin{array}{l}\text { Hard to coordinate procurement of local with regular } \\
\text { procurement }\end{array}$ & 1,208 & $26 \%$ \\
\hline Hard to find new suppliers/growers or distributors & 909 & $19 \%$ \\
\hline Hard to get information about product availability & 736 & $16 \%$ \\
\hline Hard to place orders with vendors & 298 & $6 \%$ \\
\hline Resolving problem deliveries & 171 & $4 \%$ \\
\hline $\begin{array}{l}\text { Inability to pay farmers according to farmers' needs } \\
\text { because of school district payment procedures }\end{array}$ & 363 & $8 \%$ \\
\hline No reported problems & 1,203 & $25 \%$ \\
\hline Total & 4,718 & \\
\hline
\end{tabular}


products, or if intermediaries do not pass cost savings through to SFAs. Intermediaries may not pass cost savings on to SFAs if they are able to exercise market power. Intermediary market power could limit the ability of SFAs to negotiate prices and manage procurement terms, which in turn can increase their procurement costs (Nocke and White 2007).

Although some SFAs contract with food service management companies, which hire management staff and arrange procurement, other SFAs are self-operated. Food service management companies comprise about 25\% of the food service contracting industry. The top four companies in the industry accrue $66 \%$ of revenues nationwide, indicating the potential for upstream market power (Hyland 2018). Broadline food distribution companies that often supply selfoperated SFAs are also concentrated. The top three such companies earn $60 \%$ of aggregate revenue, suggesting that even self-operated food service management may be subject to upstream market power (Technomic Inc. 2017). Despite the effort to enlist intermediaries in F2S procurement, it is unclear whether intermediaries reduce costs experienced by SFAs through increased efficiencies or increase costs through upstream market power ${ }^{1}$ Both theoretical and empirical research suggests that the potential cost reductions from intermediary efficiencies must be compared to the effects of increased market concentration (Hortascu and Syverson 2007; Ashenfelter, Hosken, and Weinberg 2015; Belleflamme and Peitz 2015).

\section{Data}

\section{Data Sources}

The 2013 F2S Census surveyed public school districts that participated in the National School Lunch Program about their F2S activities during the 20112012 academic year. The subsequent 2015 F2S Census of the 2013-2014 academic year expanded surveyed schools to include private and charter schools and refined the survey questions. In the 2015 F2S Census, 12,585 SFAs completed the survey for a response rate of $70 \%$.

SFA-level data are from both the 2013 and 2015 F2S Censuses. County-level data on population, per capita income, and the proportion of the population with a bachelor's degree are from the Bureau of Economic Analysis (2015). Countylevel food environment data on the per capita number of grocery stores and restaurants, as well as milk prices, are from the Food Environment Atlas (U.S. Department of Agriculture, Economic Research Service [USDA-ERS] 2017). Farm income is from the 2012 Census of Agriculture (USDA 2017). County-level ruralurban continuum codes (RUCCs) are available from the USDA-ERS (2013).

\footnotetext{
1 It is unusual in the literature on intermediary market power for consumers to advocate for a consolidation of suppliers in a market, as is the case when SFAs advocate for more opportunities to buy from intermediated sources instead of individually from farmers.
} 


\section{Data Set Construction}

To merge the 2013 and 2015 F2S Census data sets, we first eliminate SFAs in the 2015 Census that did not have a Common Core of Data (CCD) identification number. In some instances, the CCD number was not uniquely assigned in the 2015 F2S Census. We merge respondents in the two data sets by matching on CCD number, SFA zip code, and the first eight letters of the school name. ${ }^{2}$ We restrict our data to SFAs that have an F2S program in the 2015 Census, participate in both the 2013 and 2015 Censuses, and indicate which market channel they use to source local food products. Our resulting data set of merged F2S observations thus has 2,212 observations. ${ }^{3}$ We then merge these F2S data with the county-level data (i.e., RUCCs, socioeconomic variables, farm income, and food environment data) using Federal Information Processing Series (FIPS) county codes. There are 2,102 observations in our probit regressions. This is because we exclude observations with missing values for any of the independent variables from the regression.

\section{Variable Description}

The 2015 F2S Census asks SFAs whether school meal costs declined because of F2S program participation. This variable is equal to one if school meal costs declined and equal to zero otherwise. ${ }^{4}$

School meal costs could be influenced by characteristics of the SFAs (School), the location of the SFAs (Location), characteristics of how SFAs implement F2S programs (Implementation) (Fitzsimmons and Lass 2015; Motta and Sharma 2016), procurement challenges that SFAs experience (Problem) (Hobbs 1997; Gregoire, Arendt, and Strohbehn 2005; Conner et al. 2014; Fitzsimmons and Lass 2015; Motta and Sharma 2016), the food environment proximate to the SFAs (Environment) (Ralston et al. 2017; Botkins and Roe 2018; Christensen, Jablonski, and O'Hara 2019), and the market channel procurement strategy of SFAs (Procurement Strategy).

School variables represent the size, socioeconomic status, and demographic characteristics of SFAs. The number of students in the SFA may affect

\footnotetext{
2 We delete 10 observations from the 2015 Census in which two schools had the same CCD number, zip code, and first eight letters of the school name in common.

3 A select number of observations had either negative or zero values recorded for the number of students in the school district and/or the number of schools in the school district. In such instances, we change the value to missing.

4 The F2S Census also asks SFAs with F2S programs to report their local food expenditures in dollars. We do not use expenditures as the dependent variable because (a) food expenditures are only a subset of total school meal costs, and policy support is designed to subsidize nonfood costs; (b) we cannot measure how these expenditures may have changed from the implementation of an F2S program; and (c) we include price problem variables to account for pecuniary cost factors. Also, the accuracy of the responses to the expenditure questions is unclear because the survey instructions encouraged respondents to provide "rough estimates."
} 
economies of scale, and the square of school size tests whether this influence is nonlinear (Botkins and Roe 2018). The percentage of students eligible for free or reduced-price meals is indicative of the socioeconomic status of the student body of SFAs. We include this control variable because lower-income SFAs may be more incentivized to reduce costs. Three independent variables control for the ethnic and racial composition of the student body of SFAs (Botkins and Roe 2018). These variables represent the percentage of the student body that is black, Hispanic, and Asian.

Location variables include the state of the SFA and the metropolitan classification of the county. ${ }^{5}$ F2S policy support can vary at the state level, which could subsequently influence whether SFAs experience lower school meal costs. Other state-level factors could also influence whether meal costs changed from implementing an F2S program. As in Botkins and Roe (2018), we use the county-level RUCCs of SFAs to account for differences in population density and the distances of counties from cities. We thus include eight RUCC fixed effects (the ninth is the omitted variable). Location variables also account for the socioeconomic status of the county of SFAs: per capita income, population, and the percentage of the population with a bachelor's degree. The population variable controls for population variation within RUCC classifications. Dimitri, Hanson, and Oberholtzer (2012) found that county income levels influence local food sourcing patterns by schools, while O'Hara and Benson (2019) found the proportion of the county with a bachelor's degree to be pertinent.

Implementation variables control for differences in SFAs' implementation of F2S programs that may affect costs. Indicator variables represent whether the local food purchases include (a) fruits or vegetables, (b) fluid milk, and (c) meat or eggs. The type of local food products that SFAs purchase may influence costs if, for example, it is less costly to procure fruits and vegetables locally than fluid milk locally. We also control for F2S activities that SFAs undertake. These variables represent whether the SFA conducted taste tests, had a school garden, organized a field trip to a farm, hosted a farmer at the school, undertook promotional efforts, and integrated F2S concepts into the curriculum. Activity variables could be positively correlated with sourcing directly from a farmer if SFAs undertake costly activities to achieve educational goals. We use responses from the 2013 Census to construct the food product and F2S activity variables to avoid simultaneity.

SFAs that experience procurement challenges in local sourcing may be less likely to report lower school meal costs from F2S programming. We develop

\footnotetext{
5 We include 44 state dummy variables. Of the 2,102 observations in the probit regressions, there are no observations from the District of Columbia, Hawaii, Puerto Rico, and Alaska. We omit control variables for New Hampshire, Nevada, and Utah because all three states perfectly predict that SFAs do not reduce costs from F2S programming. These three states only have 3, 1, and 7 observations associated with them, respectively, and the results are effectively unchanged if we instead remove those 11 observations entirely. We omit Wyoming as a control variable because of multicollinearity.
} 
five Problem variables from the 20 questions regarding F2S challenges because they are highly correlated with each other. To do so, we consolidate the questions according to literature on F2S barriers and value-chain market structure (Table 1). One commonly cited barrier to F2S implementation addresses internal barriers within schools (Vogt and Kaiser 2008). We create an "on-site problem" variable that is one if schools indicate that they lack capacity to process/prepare local foods or comply with institutional regulations and policies, and zero otherwise. Another barrier is the premium price of local foods (Vo and Holcomb 2011; Boys and Fraser 2019). We create a binary "price problem" variable that takes the value of one if the SFAs indicate that they experience higher or unstable prices. Transaction costs such as gathering information, negotiating, and enforcing procurement terms are frequently cited as a barrier to F2S procurement and challenge in values-based supply chains (Gregoire, Arendt, and Strohbehn 2005; Conner et al. 2014). The "transaction problem" variable takes the value of one if the SFA struggles to obtain bids, coordinate procurement of local products with regular procurement, find new farmers or distributors, get information, place orders with vendors, resolve problem deliveries, or pay farmers according to farmers' needs; and zero otherwise. "Product problems" include seasonal availability, a lack of processed products, product shelf life/appearance, and a lack of local supply/producers (Vogt and Kaiser 2008; Oberholtzer, Dimitri, and Jaenicke 2014). The "product problem" variable takes the value of one if the SFA experiences challenges with year-round availability of key items or processed products, vendors not having items, or getting products of low quality; and zero otherwise. Finally, "distribution problems" associated with supply chain infrastructure are cited as barriers to F2S procurement and values-based supply chains (Gregoire, Arendt, and Strohbehn 2005; Oberholtzer, Dimitri, and Jaenicke 2014). The "distribution problem" variable takes the value of one if the SFA indicates that deliveries are not reliable, are not on time, or have incorrect quantities.

Four county-level variables control for the SFAs' external Food Environment. We control for the density of food outlets using the number of grocery stores per capita and the number of restaurants per capita (USDA-ERS 2017). We also include two variables used by Botkins and Roe (2018) as controls: the ratio of local milk prices to national milk prices and farm income (USDA 2017; USDA-ERS 2017). In the former case, this variable is a proxy for the relative costs of local products because fluid milk is a prominent locally sourced food product. Variation in the prices of local products could influence whether school meal costs declined from F2S programing. In the latter instance, higher levels of farm income could reflect conducive conditions for conventional commodity production. This, in turn, could be a disincentive for farmers to sell products directly to schools, thus increasing the effort SFAs must expend to procure local foods.

Procurement Strategy variables indicate whether SFAs procure local foods by purchasing local foods directly from farmers exclusively, from intermediaries 
exclusively, and from both farmers and intermediaries. ${ }^{6}$ The three variables are mutually exclusive. The "direct exclusive" variable includes procurement sources in which farmers can negotiate prices and terms with the SFA. The "direct exclusive" variable is binary. It equals one if SFAs procure local products directly from a farmer, rancher, or fisher; from a producer cooperative; at a farmers' market; and/or through a community-supported agriculture model. (We refer to such direct sourcing as purchasing directly from a "farmer" for brevity.) The "intermediated exclusive" variable includes procurement sources in which intermediaries may set prices and terms for the SFA. This is a binary variable that equals one if the SFA procures local foods exclusively through a food processor or manufacturer, distributor, food buying cooperative, food service management company, Department of Defense Fresh Program vendor, USDA Foods, food hub, and/or state F2S program office. The "both direct and intermediated" variable is a binary variable that equals one if the SFA procures local products through both direct and intermediated market channels and is equal to zero otherwise.

\section{Summary Statistics}

Twenty-two percent of SFAs in our sample reported lower school meal costs from participating in F2S programs (Table 2). Ten percent of SFAs purchased local food exclusively from a farmer, whereas $47 \%$ made such purchases directly from farmers and from intermediaries. Fruits and vegetables were the most frequently purchased local food products. The average student size of an SFA was 5,300 , and on average, $47 \%$ of students were eligible for free or reducedprice lunch. The SFAs have a balanced distribution among the geographic regions established by FNS, and $61 \%$ of the SFAs were in a metropolitan county. Nearly three-quarters of SFAs (74\%) reported problems with product quality or availability, and nearly half reported problems with product pricing.

\section{Methods}

\section{Probit Regressions}

We investigate whether SFAs report that school meal costs declined as a function of the procurement strategy they use for local products. We estimate three binary probit regressions in which the main independent variable is one of the mutually exclusive procurement strategies of interest: whether

\footnotetext{
6 The most common market channels that SFAs use for sourcing local foods are the following: distributors (65\%), individual food producers $(40 \%)$, processors/manufacturers $(38 \%)$, Department of Defense Fresh Program vendors (31\%), and USDA Foods (31\%). SFAs use the other market channels identified in the survey less than $20 \%$ of the time (Christensen, Jablonski, and O'Hara 2019).
} 
Table 2. Descriptive Statistics

\begin{tabular}{|c|c|c|c|c|c|}
\hline Variable & Mean & SD & Variable & Mean & SD \\
\hline \multicolumn{6}{|l|}{ Dependent Variable } \\
\hline Lower cost from F2S programming & 0.22 & 0.41 & & & \\
\hline Market Channel Variables & & & Instruments & & \\
\hline Purchased direct exclusive & 0.10 & 0.31 & County-level farmers' markets per 10,000 & 0.49 & 0.58 \\
\hline Purchased intermediate exclusive & 0.43 & 0.49 & County-level retail producers per 10,000 & 3.81 & 5.09 \\
\hline Purchased both direct and intermediate & 0.47 & 0.50 & & & \\
\hline \multicolumn{6}{|l|}{ Control Variables } \\
\hline School & & & Location & & \\
\hline Student size of SFA/10,000 & 0.53 & 1.09 & RUCC 1 (large metro) & 0.28 & 0.45 \\
\hline Square of student size & 1.47 & 10.92 & RUCC 2 (medium metro) & 0.20 & 0.40 \\
\hline$\%$ of Students free/reduced price lunch & 0.47 & 0.21 & RUCC 3 (small metro) & 0.13 & 0.34 \\
\hline$\%$ Students black & 0.09 & 0.20 & RUCC 4 (large adjacent nonmetro) & 0.10 & 0.30 \\
\hline \% Students Hispanic & 0.51 & 15.16 & RUCC 5 (large nonadjacent nonmetro) & 0.02 & 0.15 \\
\hline$\%$ Students Asian & 0.03 & 0.13 & RUCC 6 (medium adjacent nonmetro) & 0.13 & 0.34 \\
\hline Implementation & & & RUCC 7 (medium nonadjacent nonmetro) & 0.07 & 0.26 \\
\hline Fruits/veg. local (2011-12) & 0.62 & 0.48 & RUCC 8 (small adjacent nonmetro) & 0.02 & 0.15 \\
\hline Fluid milk local (2011-12) & 0.28 & 0.45 & County population/1,000,000 & 0.42 & 1.04 \\
\hline Meat/eggs local (2011-12) & 0.15 & 0.36 & County per capita income $/ 10,000$ & 4.27 & 1.19 \\
\hline Taste test (2011-12) & 0.29 & 0.45 & $\%$ County bachelor's degree & 0.25 & 0.10 \\
\hline School garden (2011-12) & 0.22 & 0.42 & Northeast & 0.16 & 0.37 \\
\hline Trip to farm (2011-12) & 0.19 & 0.39 & Mid-Atlantic & 0.09 & 0.29 \\
\hline Farmer visit SFA (2011-12) & 0.13 & 0.34 & Southeast & 0.14 & 0.34 \\
\hline
\end{tabular}




\begin{tabular}{llllr} 
Themed promotion (2011-12) & 0.20 & 0.40 & Midwest & 0.43 \\
Integrated F2S curriculum (2011-12) & 0.09 & 0.28 & Mountain & 0.13 \\
$\begin{array}{l}\text { Problem } \\
\text { Pricing procurement problem }\end{array}$ & 0.48 & 0.50 & Food Environment & 0.08 \\
Transaction procurement problem & 0.53 & 0.50 & County grocery stores per capita & 0.27 \\
Product procurement problem & 0.74 & 0.44 & County restaurants per capita & 0.11 \\
Distribution procurement problem & 0.29 & 0.45 & County milk price/fed. price & 0.36 \\
On-site procurement problem & 0.29 & 0.45 & County farm income (hundred million) & 0.13 \\
\hline
\end{tabular}

Notes: We calculated the statistics from the 2,102 observations used in the probit regressions. RUCC, rural-urban continuum code; SD, standard deviation; SFA, school food authority. 
SFAs procure local foods exclusively from intermediaries (regression I), whether SFAs procure local foods from both farmers and intermediaries (regression II), and whether SFAs procure local foods directly from farmers exclusively (regression III). We define the likelihood of reduced school meal costs from F2S programming as follows:

$$
P\left(y_{i}=1 \mid \mathbf{x}_{i}\right)=\Phi\left(\mathbf{x}_{i}^{\prime} \boldsymbol{\beta}\right)
$$

where $i$ denotes the SFA, $y$ takes the value of 1 if the SFA perceives that F2S programming lowers school meal costs and 0 otherwise, $\mathbf{x}$ represents SFA characteristics, $\boldsymbol{\beta}$ is a vector of parameters, and $\Phi$ is the standard normal cumulative distribution function. We report the marginal effects of each coefficient in which we evaluate the other covariates at their sample means. The SFA characteristics include the market channel procurement variable and the comprehensive list of control variables that we described in the previous section.

\section{Regional Subsamples}

We follow Brown et al. (2014) and examine subsamples of the data to discern whether there is regional variation in the influence of market channel choice on school meal costs. Regional characteristics may inform our understanding of how F2S programming can vary because of variation in agroecological conditions, distribution infrastructure, and cultural characteristics. For instance, SFAs may be more likely to reduce school meal costs when buying from intermediaries in parts of the country where there is less consolidation among food distributors or more warehouses available to assist distributors.

\section{Testing for Endogeneity}

Our parameter estimate could be endogenous if the dependent variable (perception of whether F2S programming lowers school meal costs) and key independent variables of interest (market channel procurement strategy variables) are determined simultaneously or if there are omitted independent variables. We test whether market channel procurement strategy is endogenous with two instruments: the county-level number of farmers' markets per 10,000 residents and the county-level number of farms that sell directly to retailers per 10,000 residents. We find that, given our instruments, our independent variables of interest are likely to be exogenous. We provide further detail and documentation in the supplementary Appendix.

\section{Results}

For each regression (I-III), we first present our probit regression results of whether market channel choice influences the perception that school meal 
costs declined from F2S programming. We report the marginal effects to make the coefficients easier to interpret. We then discuss the regional regression results.

\section{Probit Regression Results}

SFAs that procure local products exclusively from intermediaries have a lower probability of reducing school meal costs from F2S programming (regression I in Table 3). The probit regression coefficient is -0.25 and has a $p$ value of 0.001 . The corresponding marginal effect implies that SFAs that purchase local foods exclusively from intermediaries, relative to those that purchase at least some local foods directly from farmers, are $7 \%$ less likely to reduce school meal costs from F2S programming.

Student size has a quadratic effect on whether an SFA reduces school meal costs. The impact of student size is negative, whereas the square of student size is positive. These coefficients suggest that the likelihood that school meal costs decline from F2S programming decreases at an increasing rate as schools get bigger. SFAs that purchase fruits and vegetables locally are $4 \%$ more likely to reduce school meal costs. SFAs with product procurement problems are $8 \%$ more likely to have reduced school meal costs. Intuitively, SFAs that report pricing procurement problems are $16 \%$ less likely to report lower costs from F2S programs. Similarly, two F2S activity variables are statistically significant with opposite signs: whether the SFA undertakes promotional efforts and whether the SFA integrates F2S concepts into the curriculum. The marginal effects for these latter two variables are -0.07 and 0.09 , respectively. The pseudo- $\mathrm{R}^{2}$ is 0.12 , and the chi-square test for global significance is statistically significant.

We include county-level variables in our regression to control for the socioeconomic characteristics, food environment, and local agricultural conditions surrounding SFAs. In general, these county-level variables do not have statistically significant impacts on whether SFAs reduced school meal costs from F2S programming. One exception is the grocery store coefficient, which has a p value of 0.097 in regression I and is statistically insignificant in regressions II and III. After conditioning on the SFAs' state and RUCC classification, SFA-level factors predominately influence school meal costs.

SFAs that procure local foods from both farmers and intermediaries have a greater probability of reducing school meal costs relative to SFAs that procure local foods exclusively from either intermediaries or farmers (regression II in Table 3). The coefficient magnitude is 0.23 and has a $\mathrm{p}$ value of 0.001. The marginal effect for this market channel coefficient is 0.06. The control variables that are statistically significant in regression I are also significant in regression II with highly similar marginal effects (except for the grocery store variable, which we previously discussed). This occurs because the market channel variable is the only independent variable that changes between the two specifications. There is no statistically significant association 
Table 3. Probit Regression Results of Market Channel Choice on School Meal Costs

\begin{tabular}{|c|c|c|c|c|c|c|}
\hline Regression: & $\mathbf{I}$ & I (Marg. Eff.) & II & II (Marg. Eff.) & III & III (Marg. Eff.) \\
\hline \multicolumn{7}{|l|}{ Market Channel } \\
\hline \multirow[t]{2}{*}{ Purchased intermediate exclusive } & $-0.25^{* * *}$ & $-0.07^{* * *}$ & & & & \\
\hline & $(0.08)$ & $(0.02)$ & & & & \\
\hline \multirow[t]{2}{*}{ Purchased both direct and intermediate } & & & $0.23^{* * *}$ & $0.06^{* * *}$ & & \\
\hline & & & $(0.07)$ & $(0.02)$ & & \\
\hline \multirow[t]{2}{*}{ Purchased direct exclusive } & & & & & -0.03 & -0.01 \\
\hline & & & & & $(0.11)$ & $(0.03)$ \\
\hline \multicolumn{7}{|l|}{ School } \\
\hline \multirow[t]{2}{*}{ Student size of SFA/10,000 } & $-0.27^{* * *}$ & $-0.07^{* * *}$ & $-0.28^{* * *}$ & $-0.07^{* * *}$ & $-0.28^{* * *}$ & $-0.07^{* * *}$ \\
\hline & $(0.08)$ & $(0.02)$ & $(0.08)$ & $(0.02)$ & $(0.08)$ & $(0.02)$ \\
\hline \multirow[t]{2}{*}{ Square of student size } & $0.02^{* * *}$ & $0.006^{* * *}$ & $0.02^{* * *}$ & $0.006^{* * *}$ & $0.02^{* * *}$ & $0.006^{* * *}$ \\
\hline & $(0.01)$ & $(0.002)$ & $(0.01)$ & $(0.002)$ & $(0.01)$ & $(0.002)$ \\
\hline \multirow[t]{2}{*}{$\%$ of students free/reduced price lunch } & -0.02 & 0.00 & -0.02 & 0.00 & -0.03 & -0.01 \\
\hline & $(0.23)$ & $(0.06)$ & $(0.24)$ & $(0.06)$ & $(0.23)$ & $(0.06)$ \\
\hline \multirow[t]{2}{*}{$\%$ Students black } & -0.18 & -0.05 & -0.18 & -0.05 & -0.17 & -0.04 \\
\hline & $(0.28)$ & $(0.07)$ & $(0.28)$ & $(0.07)$ & $(0.27)$ & $(0.07)$ \\
\hline \multirow[t]{2}{*}{ \% Students Hispanic } & -0.08 & -0.02 & -0.08 & -0.02 & -0.08 & -0.02 \\
\hline & $(0.08)$ & $(0.02)$ & $(0.08)$ & $(0.02)$ & $(0.08)$ & $(0.02)$ \\
\hline \multirow[t]{2}{*}{$\%$ Students Asian } & 0.52 & 0.14 & 0.50 & 0.13 & 0.47 & 0.12 \\
\hline & $(0.54)$ & $(0.14)$ & $(0.54)$ & $(0.14)$ & $(0.55)$ & $(0.14)$ \\
\hline
\end{tabular}




\begin{tabular}{|c|c|c|c|c|c|c|}
\hline \multicolumn{7}{|l|}{ Implementation } \\
\hline \multirow[t]{2}{*}{ Fruits/veg. local (2011-12) } & $0.17^{* *}$ & $0.04^{* *}$ & $0.18^{* *}$ & $0.05^{* *}$ & $0.20^{* *}$ & $0.05^{* *}$ \\
\hline & $(0.09)$ & $(0.02)$ & $(0.09)$ & $(0.02)$ & $(0.09)$ & $(0.02)$ \\
\hline \multirow[t]{2}{*}{ Fluid milk local (2011-12) } & 0.03 & 0.01 & 0.02 & 0.01 & 0.01 & 0.00 \\
\hline & $(0.09)$ & $(0.02)$ & $(0.09)$ & $(0.02)$ & $(0.09)$ & $(0.02)$ \\
\hline \multirow[t]{2}{*}{ Meat/eggs local (2011-12) } & -0.09 & -0.02 & -0.08 & -0.02 & -0.08 & -0.02 \\
\hline & $(0.10)$ & $(0.03)$ & $(0.10)$ & $(0.03)$ & $(0.10)$ & $(0.03)$ \\
\hline \multirow[t]{2}{*}{ Taste test (2011-12) } & 0.06 & 0.02 & 0.06 & 0.02 & 0.07 & 0.02 \\
\hline & $(0.09)$ & $(0.02)$ & $(0.09)$ & $(0.02)$ & $(0.09)$ & $(0.02)$ \\
\hline \multirow[t]{2}{*}{ School garden (2011-12) } & -0.12 & -0.03 & -0.12 & -0.03 & -0.11 & -0.03 \\
\hline & $(0.09)$ & $(0.02)$ & $(0.09)$ & $(0.02)$ & $(0.09)$ & $(0.02)$ \\
\hline \multirow[t]{2}{*}{ Trip to farm (2011-12) } & 0.04 & 0.01 & 0.04 & 0.01 & 0.03 & 0.01 \\
\hline & $(0.09)$ & $(0.02)$ & $(0.09)$ & $(0.02)$ & $(0.09)$ & $(0.02)$ \\
\hline \multirow[t]{2}{*}{ Farmer visit SFA (2011-12) } & 0.07 & 0.02 & 0.07 & 0.02 & 0.08 & 0.02 \\
\hline & $(0.11)$ & $(0.03)$ & $(0.11)$ & $(0.03)$ & $(0.11)$ & $(0.03)$ \\
\hline \multirow[t]{2}{*}{ Themed promotion (2011-12) } & $-0.28^{* * *}$ & $-0.07^{* * *}$ & $-0.29^{* * *}$ & $-0.08^{* * *}$ & $-0.28^{* * *}$ & $-0.07^{* * *}$ \\
\hline & $(0.10)$ & $(0.03)$ & $(0.10)$ & $(0.03)$ & $(0.10)$ & $(0.03)$ \\
\hline \multirow[t]{2}{*}{ Integrated F2S curriculum (2011-12) } & $0.33^{* * *}$ & $0.09 * * *$ & $0.33^{* *}$ & $0.09^{* *}$ & $0.34^{* * *}$ & $0.09^{* * *}$ \\
\hline & $(0.13)$ & $(0.03)$ & $(0.13)$ & $(0.03)$ & $(0.13)$ & $(0.03)$ \\
\hline \multicolumn{7}{|l|}{ Problem } \\
\hline \multirow[t]{2}{*}{ Transaction procurement problem } & -0.03 & -0.01 & -0.03 & -0.01 & -0.03 & -0.01 \\
\hline & $(0.08)$ & $(0.02)$ & $(0.08)$ & $(0.02)$ & $(0.08)$ & $(0.02)$ \\
\hline
\end{tabular}


Table 3. Continued

\begin{tabular}{|c|c|c|c|c|c|c|}
\hline Regression: & $\mathbf{I}$ & I (Marg. Eff.) & II & II (Marg. Eff.) & III & III (Marg. Eff.) \\
\hline \multirow[t]{2}{*}{ Product procurement problem } & $0.29 * * *$ & $0.08^{* * *}$ & $0.30^{* * *}$ & $0.08^{* * *}$ & $0.30^{* * *}$ & $0.08^{* * *}$ \\
\hline & $(0.09)$ & $(0.02)$ & $(0.09)$ & $(0.02)$ & $(0.09)$ & $(0.02)$ \\
\hline \multirow[t]{2}{*}{ Distribution procurement problem } & -0.10 & -0.03 & -0.11 & -0.03 & -0.10 & -0.03 \\
\hline & $(0.08)$ & $(0.02)$ & $(0.08)$ & $(0.02)$ & $(0.08)$ & $(0.02)$ \\
\hline \multirow[t]{2}{*}{ On-site procurement problem } & -0.06 & -0.02 & -0.07 & -0.02 & -0.06 & -0.02 \\
\hline & $(0.08)$ & $(0.02)$ & $(0.08)$ & $(0.02)$ & $(0.08)$ & $(0.02)$ \\
\hline \multirow[t]{2}{*}{ Pricing procurement problem } & $-0.60^{* * *}$ & $-0.16^{* * *}$ & $-0.61^{* * *}$ & $-0.16^{* * *}$ & $-0.60^{* * *}$ & $-0.16^{* * *}$ \\
\hline & $(0.08)$ & $(0.02)$ & $(0.08)$ & $(0.02)$ & $(0.08)$ & $(0.02)$ \\
\hline \multicolumn{7}{|l|}{ Food Environment } \\
\hline \multirow[t]{2}{*}{ County population/1,000,000 } & 0.06 & 0.01 & 0.05 & 0.01 & 0.05 & 0.01 \\
\hline & $(0.04)$ & $(0.01)$ & $(0.04)$ & $(0.01)$ & $(0.04)$ & $(0.01)$ \\
\hline \multirow[t]{2}{*}{ County per capita income $/ 10,000$} & -0.03 & -0.01 & -0.04 & -0.01 & -0.04 & -0.01 \\
\hline & $(0.05)$ & $(0.01)$ & $(0.05)$ & $(0.01)$ & $(0.05)$ & $(0.01)$ \\
\hline \multirow[t]{2}{*}{$\%$ County bachelor's degree } & 0.00 & 0.00 & 0.03 & 0.01 & 0.03 & 0.01 \\
\hline & $(0.63)$ & $(0.17)$ & $(0.63)$ & $(0.17)$ & $(0.63)$ & $(0.16)$ \\
\hline \multirow[t]{2}{*}{ County grocery stores per capita } & $-0.64^{*}$ & $-0.17^{*}$ & -0.62 & -0.16 & -0.60 & -0.16 \\
\hline & $(0.40)$ & $(0.10)$ & $(0.39)$ & $(0.10)$ & $(0.39)$ & $(0.10)$ \\
\hline \multirow[t]{2}{*}{ County restaurants per capita } & 0.07 & 0.02 & 0.08 & 0.02 & 0.06 & 0.02 \\
\hline & $(0.12)$ & $(0.03)$ & $(0.12)$ & $(0.03)$ & $(0.12)$ & $(0.03)$ \\
\hline \multirow[t]{2}{*}{ County milk price/fed. price } & 0.65 & 0.17 & 0.64 & 0.17 & 0.61 & 0.16 \\
\hline & $(0.53)$ & $(0.14)$ & $(0.53)$ & $(0.14)$ & $(0.52)$ & $(0.14)$ \\
\hline
\end{tabular}




\begin{tabular}{|c|c|c|c|c|c|}
\hline County farm income (hundred million) & $\begin{array}{c}-0.03 \\
(0.05)\end{array}$ & $\begin{array}{c}-0.01 \\
(0.01)\end{array}$ & $\begin{array}{c}-0.03 \\
(0.05)\end{array}$ & $\begin{array}{c}-0.01 \\
(0.01)\end{array}$ & $\begin{array}{c}-0.03 \\
(0.05)\end{array}$ \\
\hline Intercept, RUCC F.E., state F.E. & Yes & Yes & Yes & Yes & Yes \\
\hline Observations & 2,102 & & 2,102 & & 2,102 \\
\hline Akaike information criterion & 2,098 & & 2,098 & & 2,109 \\
\hline Bayesian information criterion & 2,555 & & 2,556 & & 2,566 \\
\hline Pseudo- $R^{2}$ & 0.12 & & 0.12 & & 0.12 \\
\hline LR chi-square test (global signif.) & $266^{* * *}$ & & $265^{* * *}$ & & $255^{* * *}$ \\
\hline
\end{tabular}

Notes: Parameter estimate (standard error). Asterisks $\left({ }^{* *},{ }^{* *}\right.$, and ${ }^{*}$ ) indicate significance at the $0.01,0.05$, and 0.1 levels, respectively. F2S, farm to school; F.E., fixed effects; RUCC, rural-urban continuum code; SFA, school food authority. 
between SFAs that purchase local foods directly from farmers exclusively and lower school meal costs (regression III in Table 3).

\section{Regional Subsamples}

We estimate 21 distinct regressions-one for each market channel/region combination-to obtain the coefficients that we present in Table 4. For brevity, we only present the market channel coefficient from each regression. There is no association between market channel choice and reducing school meal costs in the Northeast, Southeast, Southwest, and Western regions. Our findings in each of the Mid-Atlantic, Midwest, and Mountain regions are consistent with the national-level results. In each of the three regions, purchasing exclusively from intermediaries has a negative impact on the probability that an SFA reduces school meal costs. Each of these three coefficients have $p$ values of less than 0.05. Also, in the Mid-Atlantic and Mountain regions, local purchasing from both farmers and intermediaries increases the likelihood of reduced school meal costs. There is no association between purchasing directly from farmers exclusively and reduced school meal costs in any of the seven regions, which is also consistent with our national-level results.

\section{Discussion}

Exclusively purchasing local foods from intermediaries decreases the probability that SFAs reduce school meal costs. One explanation for this result is that intermediaries may not achieve cost savings when aggregating from local farmers. Another possibility is that they do achieve cost savings but do not pass those cost savings along to SFAs. Yet another possible explanation is that farmers may have nonpecuniary objectives for selling directly to schools and thus may be more willing to sell foods at affordable prices in order to facilitate the transaction. Our results are inconsistent with previous literature that suggests intermediated market channels will help reduce F2S costs (Vogt and Kaiser 2008; Ralston et al. 2017) but consistent with literature documenting that nonpecuniary factors can be important in a farmer's decision to sell to schools (Conner et al. 2014; Fitzsimmons and Lass 2015). Although the latter studies occurred with a small number of farmers within a narrow geographic region, we establish that this result holds at a national level. Our results are also consistent with Christensen, Jablonski, and O'Hara (2019), who found that per capita local expenditures were negatively correlated with SFAs that procured local foods directly from farmers. The regions in which our results are most pronounced are the Mid-Atlantic, Midwest, and Mountain regions.

We also find that purchasing local foods from both farmers and intermediaries increases the probability that SFAs reduce school meal costs from F2S programs. This could occur if SFAs that procure local foods from a variety of market channels are able to negotiate more effectively or identify 
Table 4. Impacts of Market Channel Choice on School Meal Costs by Region

\begin{tabular}{|c|c|c|c|c|c|c|c|}
\hline & Northeast & $\begin{array}{c}\text { Mid- } \\
\text { Atlantic }\end{array}$ & Southeast & Midwest & Mountain & Southwest & Western \\
\hline $\begin{array}{l}\text { Purchased direct } \\
\text { exclusive }\end{array}$ & $\begin{array}{c}-0.06 \\
(0.34)\end{array}$ & $\begin{array}{c}-0.21 \\
(0.45)\end{array}$ & $\begin{array}{l}-0.27 \\
(0.41)\end{array}$ & $\begin{array}{c}0.14 \\
(0.23)\end{array}$ & $\begin{array}{c}-0.43 \\
(0.29)\end{array}$ & $\begin{array}{c}0.23 \\
(0.62)\end{array}$ & $\begin{array}{c}-0.42 \\
(0.41)\end{array}$ \\
\hline $\begin{array}{l}\text { Purchased } \\
\text { intermediate } \\
\text { exclusive }\end{array}$ & $\begin{array}{c}-0.30 \\
(0.21)\end{array}$ & $\begin{array}{c}-0.87^{* *} \\
(0.36)\end{array}$ & $\begin{array}{c}-0.07 \\
(0.25)\end{array}$ & $\begin{array}{c}-0.33^{* *} \\
(0.17)\end{array}$ & $\begin{array}{c}-0.58^{* *} \\
(0.29)\end{array}$ & $\begin{array}{c}0.26 \\
(0.39)\end{array}$ & $\begin{array}{c}-0.10 \\
(0.21)\end{array}$ \\
\hline $\begin{array}{l}\text { Purchased both } \\
\text { direct and } \\
\text { intermediate }\end{array}$ & $\begin{array}{c}0.28 \\
(0.20)\end{array}$ & $\begin{array}{l}0.75^{* *} \\
(0.31)\end{array}$ & $\begin{array}{c}0.02 \\
(0.23)\end{array}$ & $\begin{array}{c}0.23 \\
(0.15)\end{array}$ & $\begin{array}{l}0.75^{* * *} \\
(0.25)\end{array}$ & $\begin{array}{l}-0.30 \\
(0.36)\end{array}$ & $\begin{array}{c}0.20 \\
(0.20)\end{array}$ \\
\hline $\begin{array}{l}\text { FNS F2S regional } \\
\text { definitions }\end{array}$ & $\begin{array}{l}\text { CT, ME, MA, } \\
\text { NH, NY, RI, } \\
\text { VT }\end{array}$ & $\begin{array}{l}\text { DE, DC, MD, } \\
\text { NJ, PA, VA, } \\
\text { WV }\end{array}$ & $\begin{array}{l}\text { AL, FL, GA, KY, } \\
\text { MS, NC, SC, TN }\end{array}$ & $\begin{array}{l}\text { IL, IN, MI, } \\
\text { MN, OH, WI }\end{array}$ & $\begin{array}{l}\text { CO, IA, KS, MO, } \\
\text { MT, NE, ND, SD, } \\
\text { UT, WY }\end{array}$ & $\begin{array}{l}\text { AR, LA, NM, } \\
\text { OK, TX }\end{array}$ & $\begin{array}{c}\text { AK, AZ, CA, } \\
\text { HI, ID, NV, } \\
\text { OR, WA }\end{array}$ \\
\hline Observations & 339 & 189 & 287 & 503 & 275 & 171 & 338 \\
\hline
\end{tabular}

Notes: Parameter estimate (standard error). Asterisks $\left({ }^{* * *},{ }^{* *}\right.$, and ${ }^{*}$ ) indicate significance at the $0.01,0.05$, and 0.1 levels, respectively. We estimate three regressions each for each of the seven regions. We only report the market channel coefficients for brevity. We consolidated RUCCs (rural-urban continuum codes) in regressions in which they predicted lower costs perfectly. FNS, Food and Nutrition Service; F2S, farm to school. 
the most cost-effective local foods. For example, a farmer may sell food at a lower price to an SFA that is also procuring local foods from intermediaries vis-à-vis those that are not. We do not find that purchasing local foods exclusively directly from farmers affects reduced school meal costs. One possible reason why this effect is statistically insignificant is because a proportionally small number of SFAs procure local foods in this way, so we may not have a large enough sample to estimate an effect.

We show in the Appendix that one of our instruments, the density of direct retail producers, has a negative influence with statistical significance on the probability that SFAs source local foods exclusively from intermediaries. The endogeneity test from this regression fails to reject the null hypothesis that purchasing local foods exclusively from intermediaries is exogenous. That is, we fail to uncover evidence that the choice to purchase exclusively from intermediaries is determined simultaneously alongside a perception that such purchases lower costs. So, our instrumental variable results enable us to compare SFAs that procured from intermediaries exclusively and those that purchased at least some products directly from farmers under the assumption that market channel choice is exogenous.

Our instruments are uncorrelated with SFAs that procure local foods from both intermediaries and farmers. We cannot, therefore, conclude this market channel is exogenous from our instrumental variable tests. Nonetheless, there are reasons why exogeneity may be a reasonable assumption. First, if one of the market channel variables is exogenous, it logical that the other market channel variables are as well. Second, as we discuss elsewhere in the text, simultaneity may be unlikely if the decision of SFAs to source directly from farmers is made for nonpecuniary purposes.

Of the five distinct procurement problems, the pricing procurement problem coefficients have the largest magnitudes in absolute value and likewise have low $\mathrm{p}$ values. This variable reflects SFAs that experience challenges with sourcing locally because of price premiums or unstable product prices. SFAs that experience such problems, intuitively, are less likely to report that F2S programming decreases school meal costs. SFAs that reported problems with procuring local products are more likely to report lower costs. This coefficient could be positive if SFAs with procurement problems purchase less local food, and the costs associated with local food procurement are positively correlated with the magnitude purchased.

Two of the six variables that reflect SFA-level F2S activities are statistically significant. SFAs that undertake themed promotions for local foods have a lower probability of reporting lower school meal costs from F2S programming. This result could occur if such promotions are effort intensive and the costs of these initiatives are absorbed within the budgets of SFAs. Schools that integrated F2S concepts into their curriculum are more likely to report lower costs. This result could arise if this work is performed by teachers in the classroom and is therefore less likely to require additional administrative effort by SFA personnel. 
We caution, however, against drawing definitive conclusions about how particular procurement challenges and F2S activities affect school meal costs because the individual procurement challenge variables and individual activity variables are highly correlated within each category (see Tables A4 and A5 in the Appendix). We include procurement challenge and F2S activity variables to control for whether the statistical significance of the market channel coefficients is robust to the inclusion of SFA-level attributes that could be both correlated with market channel choice and influence school meal costs.

Botkins and Roe (2018) found that school size had a positive impact on F2S participation at a decreasing rate. We find that among SFAs with F2S programs, school size has a negative influence on reducing school meal costs at an increasing rate. This result may arise if smaller SFAs are less efficient in providing school meals than larger schools. Thus, smaller SFAs may be able to realize cost savings from changing procurement practices until they reach a threshold size. Further, after we include state and RUCC fixed effects, changes in school meal costs appear to be predominately influenced by SFAlevel decisions and attributes. This result may occur because of the idiosyncratic way that SFAs implement F2S programs.

\section{Conclusion}

Whether and by what means SFAs may reduce school meal costs via participation in F2S programs has not received extensive attention. However, the influence of market channel choice has important policy implications because of the possibility that F2S programs can scale up by sourcing through intermediaries. We find that market channel procurement strategies can contribute to reduced school meal costs. Our findings suggest the conditions under which F2S program implementation may be more selfsustaining in the long run, perhaps in the absence of policy support. Our results contradict the hypothesis that intermediated channels both realize cost reductions and pass those savings along the supply chain. However, because we do not observe specific cost data, we are not able to determine how this occurs. Do intermediated channels not create significant efficiencies, or do they create efficiencies but not pass them through the supply chain?

Researching the effects of market channels on F2S program costs is valuable for the effective administration and implementation of F2S programs. Perhaps a reason why the relationship between market channel choice and school meal costs has not received as much attention in the literature is that the USDA's F2S Census does not provide data that quantify market channel-specific costs. In this article, we exploit the breadth of information provided by the F2S Census to investigate this topic. We model a variable that represents aggregate costs, which encompass both food expenditures and nonfood transaction and implementation costs. Because F2S policies often aim to reduce the food service transaction and administrative costs of sourcing 
locally, and are not designed to subsidize expenditures for locally procured foods, the aggregate change in school meal costs is the measure that is relevant for F2S policy.

Another reason that F2S research may not focus on the relationship between market channel choice and lower costs is that, as we demonstrate in the Appendix, it is challenging to identify a valid instrument using observational data. However, F2S programs in the United States are not awarded to schools through a randomized process, like a lottery. Given how critical this topic is for assessing the financial sustainability of F2S programming over time, it is important for researchers to disentangle the relationship between market channels and costs to the best extent possible with observational data. Our research represents one of the first efforts to address this issue.

The F2S survey questions are designed to encourage SFAs to respond, and the parsimonious nature of the survey presents limitations. One limitation of the survey is that the question regarding school meal costs reflects the perception of SFAs regarding whether their school meal costs were reduced through participation in F2S programs. SFAs were not asked to undertake any calculations to arrive at their conclusion or to elaborate on how their school meal costs declined. The F2S Census does not ask F2S SFAs if their school meal costs increased and does not ask non-F2S SFAs questions about trends in school meal costs. More detailed data collection efforts into the components of school meal budgets would be valuable in identifying how school procurement strategies can be most effectively deployed given budgetary constraints.

USDA FNS awarded 437 F2S grants between 2013 and 2018. Seventy-six percent of these have been awarded to school districts and nonprofits, and only six have been awarded to organizations that represent agricultural producers. A possible reason behind this phenomenon is the nonpecuniary motivations of producers in participating in these markets (Izumi, Wright, and Hamm 2010; Conner et al. 2012, 2014; Matts et al. 2016). The F2S Census does not ask SFAs any questions about how their F2S programming is financially supported. Nonetheless, unanswered questions for future research include the following: Are F2S grant awards predominately being used to support direct purchases from farmers, which would be consistent with the name and branding of the program? Or are the awards predominately being used for SFAs to increase purchases from intermediaries, if such purchases are less cost effective? An assessment of the market channels being supported by F2S grants would inform which types of suppliers are the beneficiaries of these awards.

\section{Disclaimer}

The findings and conclusions in this publication are those of the authors and should not be construed to represent any official USDA or U.S. Government determination or policy. 


\section{Acknowledgments}

The authors appreciate the opportunity to present a preliminary version of the paper at the Northeastern Agricultural and Resource Economics Association 2018 preconference workshop.

\section{Financial support}

This research received no specific grant funding from any funding agency or commercial or not-for-profit sectors.

\section{Conflict of interest}

None.

\section{Transparency and openness promotion statement}

All the data that we used in this study are publicly available. We provide links to the data sets that we used in the "References" section.

\section{Supplementary material}

The supplementary material for this article can be found at https://doi.org/10. 1017 /age.2019.18

\section{References}

Angrist, J.D., and J. Pischke. 2009. Mostly Harmless Econometrics: An Empiricist's Companion. Princeton, NJ: Princeton University Press.

Ashenfelter, O.C., D.S. Hosken, and M.C. Weinberg. 2015. "Efficiencies Brewed: Pricing and Consolidation in the US Beer Industry." Rand Journal of Economics 46(2): 328-361.

Bartlett, S., F. Glantz, and C. Logan. 2008. School Lunch and Breakfast Cost Study - II: Final Report. Food and Nutrition Service, U.S. Department of Agriculture, Alexandria, VA.

Baum, C.F., M.E. Schaffer, and S. Stillman. 2003. "Instrumental Variables and GMM: Estimation and Testing." Stata Journal 3(1): 1-31.

Belleflamme, P., and M. Peitz. 2015. Industrial Organization: Markets and Strategies. Cambridge, UK: Cambridge University Press.

Benson, M. 2014. "Exploring Extension Involvement in Farm to School Program Activities." Journal of Extension 52(4): 4FEA4.

Botkins, E.R., and B. Roe. 2018. "Understanding Participation in Farm to School Programs: Results Integrating School and Supply-Side Factors." Food Policy 74: 126-137.

Boys, K.A., and A.M. Fraser. 2019. "Linking Small Fruit and Vegetable Farmers and Institutional Foodservice Operations: Marketing Challenges and Considerations." Renewable Agriculture and Food Systems 34(3): 226-238.

Brown, J., S. Goetz, M. Ahearn, and K. Liang. 2014. "Linkages between Community Focused Agriculture, Farm Sales, and Regional Growth." Economic Development Quarterly 28(1): 5-16. 
Brown, J., and C. Tousey. 2019. "Rising Market Concentration and the Decline of Food Price Shock Pass-Through to Core Inflation." Research Working Paper 19-02, Federal Reserve Bank of Kansas City, Kansas City, MO.

Bureau of Economic Analysis (BEA). 2015. "Regional Economic Accounts.” BEA, Washington, DC. Available at http://bea.gov/regional/index.htm (accessed July 11, 2016).

Centers for Disease Control and Prevention (CDC). 2018. "Childhood Obesity Prevention." CDC, Atlanta, GA. Available at https://www.cdc.gov/healthyschools/obesity/index.htm (accessed March 27, 2018).

Christensen, L.O., B.B.R. Jablonski, and J.K. O’Hara. 2019. “School Districts and Their Local Food Supply Chains." Renewable Agriculture and Food Systems 34(3): 207-215.

Colasanti, K.J.A., C. Matts, and M.W. Hamm. 2012. "Results from the 2009 Michigan Farm to School Survey: Participation Grows from 2004." Journal of Nutrition Education and Behavior 44(4): 343-349.

Conner, D., B. King, J. Kolodinsky, E. Roche, C. Koliba, and A. Trubek. 2012. "You Can Know Your School and Feed It Too: Vermont Farmers' Motivations and Distribution Practices in Direct Sales to School Food Services." Agriculture and Human Values 29(3): 321-332.

Conner, D.S., N. Sevoian, S.N. Heiss, and L. Berlin. 2014. "The Diverse Values and Motivations of Vermont Farm to Institution Supply Chain Actors." Journal of Agricultural and Environmental Ethics 27(5): 695-713.

Dimitri, C., J.C. Hanson, and L. Oberholtzer. 2012. "Local Food in Maryland Schools: A Real Possibility or a Wishful Dream?" Journal of Food Distribution Research 43(2): 112-128.

Fitzsimmons, J., and D.A. Lass. 2015. Costs and Returns to New England Farmers in the Farmto-Institution Supply Chain. University of Massachusetts Amherst, Amherst.

Fitzsimmons, J., N. Lavoie, and D. Lass. 2018. "Direct or Local? Modeling Equilibria in Local Foods Markets." Selected paper presented at the 2018 NAREA Pre-Conference Workshop, Advances in the Economic Analysis of Food System Drivers and Effects, Philadelphia, PA.

Gregoire, M.B., S.W. Arendt, and C. Strohbehn. 2005. "Iowa Producers' Perceived Benefits and Obstacles in Marketing to Local Restaurants and Institutional Foodservice Operations." Journal of Extension 43(1): 1RBI1.

Guevara, C.A. 2018. "Overidentification Tests for the Exogeneity of Instruments in Discrete Choice Models." Transportation Research Part B: Methodological 114: 241-253.

Hobbs, J.E. 1997. "Measuring the Importance of Transaction Costs in Cattle Marketing." American Journal of Agricultural Economics 79(4): 1083-1095.

Hortaçsu, A., and C. Syverson. 2007. "Cementing Relationships: Vertical Integration, Foreclosure, Productivity, and Prices." Journal of Political Economy 115(2): 250-301.

Hyland, R. 2018. Food Service Contractors in the U.S. IBISWorld Industry Report 72231, IBISWorld, New York, NY.

Izumi, B.T., D.W. Wright, and M.W. Hamm. 2010. "Market Diversification and Social Benefits: Motivations of Farmers Participating in Farm to School Programs." Journal of Rural Studies 26(4): 374-382.

Jones, S.J., C. Childers, A.T. Weaver, and J. Ball. 2015. "SC Farm-to-School Programs Encourages Children to Consume Vegetables." Journal of Hunger and Environmental Nutrition 10(4): 511-525.

Joshi, A., A.M. Azuma, and G. Feenstra. 2008. "Do Farm-to-School Programs Make a Difference? Findings and Future Research Needs." Journal of Hunger and Environmental Nutrition 3(23): 229-246.

Lehnerd, M., J. Sacheck, T. Griffin, J. Goldberg, and S. Cash. 2018. “Farmers' Perspectives on the Adoption and Impacts of Nutrition Incentive and Farm to School Programs." Journal of Agriculture, Food Systems, and Community Development 8(1): 147-165.

Lyson, H.C. 2016. "National Policy and State Dynamics: A State-Level Analysis of the Factors Influencing the Prevalence of Farm to School Programs in the United States." Food Policy 63: 23-35. 
Matts, C., D.S. Conner, C. Fisher, S. Tyler, and M.W. Hamm. 2016. "Farmer Perspectives of Farm to Institution in Michigan: 2012 Survey Results of Vegetable Farmers." Renewable Agriculture and Food Systems 31(1): 60-71.

McCarthy, A.C., A.S. Steiner, and R.F. Houser. 2017. "Do State Farm-to-School-Related Laws Increase Participation in Farm-to-School Programs?" Journal of Hunger and Environmental Nutrition 12(4): 466-480.

Motta, V., and A. Sharma. 2016. "Benefits and Transaction Costs of Purchasing Local Foods in School Districts." International Journal of Hospitality Management 55: 81-87.

National Farm to School Network (NFSN). 2016. "Growth of Farm to School in the U.S. (19972014)." NFSN, Washington, DC. Available at http://www.farmtoschool.org/resources-main/ growth-of-farm-to-school-in-the-u-s-1997-2014-graphic (accessed October 30, 2017).

Nocke, V., and L. White. 2007. "Do Vertical Mergers Facilitate Upstream Collusion?" American Economic Review 97(4): 1321-1339.

Oberholtzer, L., C. Dimitri, and E.C. Jaenicke. 2014. "Examining U.S. Food Retailers' Decisions to Procure Local and Organic Produce from Farmer Direct-to-Retail Supply Chains." Journal of Food Products Marketing 20(4): 345-361.

O'Hara, J.K., and M. Benson. 2019. "The Impact of Local Agricultural Production on Farm to School Expenditures." Renewable Agriculture and Food Systems 34(3): 216-225.

Ollinger, M., and J. Guthrie. 2015. Economies of Scale, the Lunch-Breakfast Ratio, and the Cost of USDA School Breakfasts and Lunches. ERR No. 196, Economic Research Service, U.S. Department of Agriculture, Washington, DC.

Ollinger, M., K. Ralston, and J. Guthrie. 2011. School Foodservice Costs: Location Matters. ERR No. 117, Economic Research Service, U.S. Department of Agriculture, Washington, DC.

Pizer, S.D. 2016. "Falsification Testing of Instrumental Variables Methods for Comparative Effectiveness Research." Health Services Research 51(2): 790-811.

Ralston, K., E. Beaulieu, J. Hyman, M. Benson, and M. Smith. 2017. Daily Access to Local Foods for School Meals: Key Drivers. EIB No. 168, Economic Research Service, U.S. Department of Agriculture, Washington, DC.

Ralston, K., and C. Newman. 2015. School Meals in Transition. EIB No. 143, Economic Research Service, U.S. Department of Agriculture, Washington, DC.

Sexton, R.J., and T. Xia. 2018. "Increasing Concentration in the Agricultural Supply Chain: Implications for Market Power and Sector Performance." Annual Review of Resource Economics 10: 229-251.

Slusser, W.M., W.G. Cumberland, B.L. Browdy, L. Lange, and C. Neumann. 2007. “A School Salad Bar Increases Frequency of Fruit and Vegetable Consumption among Children Living in Low-Income Households." Public Health Nutrition 10(12): 1490-1496.

Technomic Inc. 2017. "Technomic Ranks Performance of Top Broadline Foodservice Distributors." PR Newswire, June 29.

U.S. Department of Agriculture (USDA). 2017. “Census of Agriculture.” USDA, Washington, DC. Available at https://www.agcensus.usda.gov/Publications/2012/ (accessed April 11, 2018).

U.S. Department of Agriculture, Economic Research Service (USDA-ERS). 2013. "Rural-Urban Continuum Codes." USDA-ERS, Washington, DC. Available at https://www.ers.usda.gov/dataproducts/rural-urban-continuum-codes.aspx\#.UYJuVEpZRvY (accessed March 20, 2018).

— 2017. "Food Environment Atlas.” USDA-ERS, Washington, DC. Available at https:// www.ers.usda.gov/foodatlas/ (accessed March 20, 2018).

U.S. Department of Agriculture, Food and Nutrition Service (USDA-FNS). 2017. "The Farm to School Census." USDA-FNS, Alexandria, VA. Available at https://farmtoschoolcensus.fns. usda.gov/ (accessed October 12, 2017).

Vo, A., and R.B. Holcomb. 2011. "Impacts of School District Characteristics on Farm-to-School Program Participation: The Case for Oklahoma." Journal of Food Distribution Research 42(3): 43-59.

Vogt, R.A., and L.L. Kaiser. 2008. "Still a Time to Act: A Review of Institutional Marketing of Regionally-Grown Food." Agriculture and Human Values 25(2): 241-255. 